\title{
Strigolactone Deficiency Confers Resistance in Tomato Line SL-ORT1 to the Parasitic Weeds Phelipanche and Orobanche spp.
}

\author{
Evgenia Dor, Koichi Yoneyama, Smadar Wininger, Yoram Kapulnik, \\ Kaori Yoneyama, Hinanit Koltai, Xiaonan Xie, and Joseph Hershenhorn
}

First and eighth authors: Institute of Plant Protection, Agricultural Research Organization (ARO), Newe Ya'ar Research Center, P.O. Box 1021, Ramat Yishay 30095, Israel; second, fifth, and seventh authors: Weed Science Center, Utsunomiya University, 350 Mine-machi, Utsunomiya 321-8505, Japan; and third, fourth, and sixth authors: Institute of Plant Sciences, ARO, the Volcani Center, P.O. Box 6, Bet Dagan 50250, Israel.

Accepted for publication 7 September 2010.

\begin{abstract}
Dor, E., Yoneyama, K., Wininger, S., Kapulnik, Y., Yoneyama, K., Koltai, H., Xie, X., and Hershenhorn, J. 2011. Strigolactone deficiency confers resistance in tomato line $S L-O R T 1$ to the parasitic weeds Phelipanche and Orobanche spp. Phytopathology 101:213-222.

The parasitic flowering plants of the genera Orobanche and Phelipanche (broomrape species) are obligatory chlorophyll-lacking root-parasitic weeds that infect dicotyledonous plants and cause heavy economic losses in a wide variety of plant species in warm-temperate and subtropical regions. One of the most effective strategies for broomrape control is crop breeding for broomrape resistance. Previous efforts to find natural broomrape-resistant tomato (Solanum lycopersicon) genotypes were unsuccessful, and no broomrape resistance was found in any wild tomato species. Recently, however, the fast-neutron-mutagenized tomato

mutant $S L-O R T 1$ was found to be highly resistant to various Phelipanche and Orobanche spp. Nevertheless, SL-ORT1 plants were parasitized by Phelipanche aegyptiaca if grown in pots together with the susceptible tomato cv. M-82. In the present study, no toxic activity or inhibition of Phelipanche seed germination could be detected in the SL-ORTI root extracts. SL-ORT1 roots did not induce Phelipanche seed germination in pots but they were parasitized, at the same level as M-82, after application of the synthetic germination stimulant GR24 to the rhizosphere. Whereas liquid chromatography coupled to tandem mass spectrometry analysis of root exudates of M-82 revealed the presence of the strigolactones orobanchol, solanacol, and didehydro-orobanchol isomer, these compounds were not found in the exudates of $S L-O R T 1$. It can be concluded that $S L$ ORT1 resistance results from its inability to produce and secrete natural germination stimulants to the rhizosphere.
\end{abstract}

Broomrape plants (Phelipanche and Orobanche spp.) are obligate, chlorophyll-lacking root parasites of dicotyledonous crops, which depend entirely on their hosts for all nutritional requirements (23). These parasitic weeds are widespread in Mediterranean areas in Asia, Africa, and Southern and Eastern Europe and cause severe damage to vegetable and field crops worldwide (12). Several crops, belonging to various botanical families, have been found to be resistant or tolerant to broomrape plants. The development of improved cultivars with resistance to a single pathogen is often straightforward when a good source of resistance is available. Unfortunately, this is only rarely the case with parasitic weeds, where resistance is difficult to access, scarce, complex, and of low heritability, making breeding for resistance a difficult task $(28,31,32)$.

Intensive research has revealed several resistance mechanisms against root-parasitic weeds in various crops (37). In some cases, the resistance is based on several mechanisms, synchronized in time and space $(12,25)$. Phytoalexin induction (33), high levels of peroxidase activity $(9,24)$, lignification of host endodermis and xylem vessels (4,27), cell-wall deposition (23), development of an encapsulation layer in the cortical parenchyma $(25,27)$, and sealing of host xylem vessels by mucilage deposition (26) have all been demonstrated as resistance mechanisms against broomrape species. Protein crosslinking in the host cell walls has also been proposed as a mechanism of defense in pea, halting penetration of

Corresponding author: E. Dor; E-mail address: evgeniad@ volcani.agri.gov.il

doi:10.1094/PHYTO-07-10-0184

(c) 2011 The American Phytopathological Society the parasite in the host root cortex before reaching the central cylinder, with accumulation of $\mathrm{H}_{2} \mathrm{O}_{2}$, peroxidases, and callose in neighboring cells (24).

Callose deposition and reactive oxygen species (ROS) production are also typical responses to biotic and abiotic stresses in plants and are involved in the interaction between plants and their parasites $(25,26)$. Induction of pathogenesis-related $(\mathrm{PR})$ proteins in susceptible tobacco roots (13) and the involvement of wallassociated kinase (LeWAK) in tomato's early perception of Phelipanche ramosa (19) have been demonstrated. The most promising tomato line reported to date as resistant to $P$. ramosa and $P$. aegyptiaca was obtained in Russia (1). However, this line failed to show resistance in other locations (11).

The germination of all Orobanche and Phelipanche spp. depends on the reception of chemical stimulation from host roots (23). So far, three different types of compounds have been identified as germination stimulants for root-parasitic plants: dihydroquinones, sesquiterpene lactones, and strigolactones. Strigolactones also act as host-recognition signals for symbiotic arbuscular mycorrhizal fungi, and they have been recently reported as plant hormones that inhibit shoot branching (38). Low induction of broomrape seed germination by host-root exudates has recently been found in some accessions of a range of legumes, including vetch, pea, chickpea, grass pea $(25,29,30,34)$, and sunflower $(15,17,18)$. It was suggested that this trait can be used to avoid parasitism by parasitic weeds (37). The production of reduced levels of germination stimulants is one of the key sources for Striga spp. resistance in sorghum $(6,14)$.

The objective of the present study was to elucidate the resistance mechanism of $S L-O R T 1$, a tomato mutant that has recently been characterized as a broomrape-resistant line $(2,16)$. 


\section{MATERIALS AND METHODS}

Chemicals. GR24 was purchased from Prof. B. Zwanenburg (University of Nijmegen, The Netherlands). The other analytical grade chemicals and high-performance liquid chromatography (HPLC) solvents were obtained from Kanto Chemical Co. Ltd. (Tokyo), Wako Pure Chemical Industries Ltd. (Osaka, Japan), and Biolab Ltd. (Jerusalem, Israel).

Plant material. Seed of Egyptian broomrape ( $P$. aegyptiaca (Pers.) Pomel, syn. Orobanche aegyptiaca Pers.) were collected from plants parasitizing tomato in infested tomato fields in Kibbutz Bet-Ha'shita in the Eastern part of Israel. P. aegyptiaca seed were separated and dried by sifting through mesh $(30-\mu \mathrm{m}$ mesh size). Seed were stored in the dark at $4^{\circ} \mathrm{C}$ until use.

The commercial tomato (Solanum lycopersicon) cv. M-82 was obtained from Tarsis Agricultural Chemicals Ltd. (Petah Tikva, Israel). Seed of the resistant line SL-ORT1 were produced at Newe Ya'ar Research Center, Agricultural Research Organization, Israel. Tomato line M-82 was selfed and F4 and F5 plants were used in all experiments.

The tomato mutant $S L-O R T 1$, which is resistant to broomrape, was obtained by mutagenesis of tomato cv. M-82, using the fastneutron method (2). The mutant line was selfed several times and F5 plants were used in all experiments.

Search for toxic activity of $S L-O R T 1$ and M-82 root extracts on $\boldsymbol{P}$. aegyptiaca seed germination. Both tomato lines were grown in 4-liter pots. Medium-heavy clay-loam soil (55\% clay, $25 \%$ silt, $20 \%$ sand, $14 \% \mathrm{CaCO}_{3}$, and $2 \%$ organic matter; $\mathrm{pH} 7.1$ to 7.2 ) was artificially infested with $P$. aegyptiaca seed (15 ppm) by mixing the soil and seed in a cement mixer for $10 \mathrm{~min}$ to homogeneity. The pots were placed in a greenhouse under longday conditions (14 h of daylight). Tomato lines grown in noninfested soil served as controls. In this experiment, 4-liter pots were used to obtain a large root volume that would provide sufficient amounts of root extract for analysis. The experiment was conducted with 30 replicates per treatment. Two months after planting, the soil root system was gently washed; roots were weighed and then stored at $-20^{\circ} \mathrm{C}$.

Roots $(10 \mathrm{~g})$ were homogenized with a mortar and pestle in $60 \mathrm{ml}$ of hexane. The slurry was gently stirred for $1 \mathrm{~h}$ at room temperature and filtered through Whatman no. 3 filter paper (Whatman International, Maidstone, UK) under vacuum into a

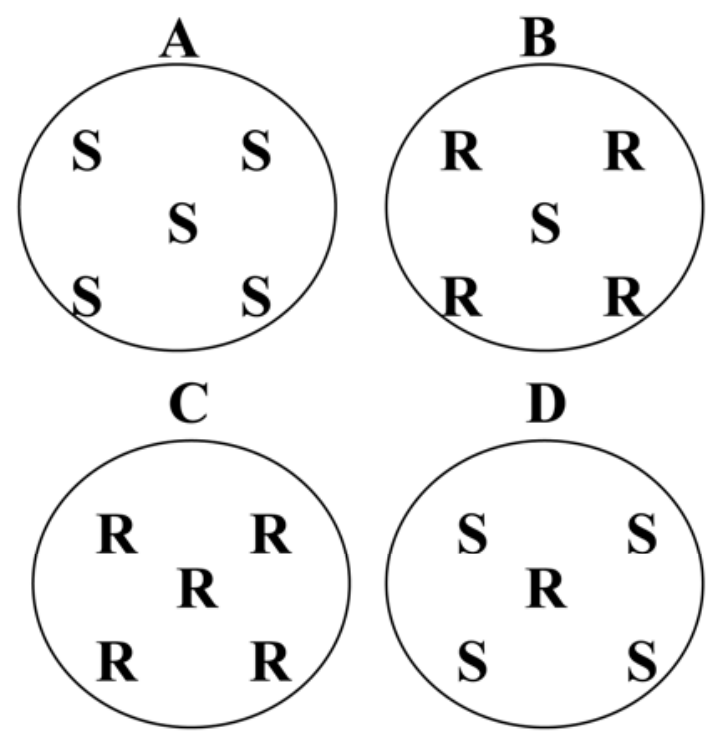

Fig. 1. Scheme of $S L-O R T 1$ and M-82 plants grown together in the same pot. A, One M-82 (S) plant surrounded by four M-82 plants. B, One M-82 plant surrounded by four $S L-O R T 1$ (R) plants. C, One $S L-O R T 1$ plant surrounded by four $S L-O R T 1$ plants. D, One $S L-O R T 1$ plant surrounded by four M-82 plants.
Buchner flask. The homogenate left on the filter paper was then re-extracted in the same way with chloroform, followed by ethyl acetate, methanol, and water. The solvents were dried under reduced pressure at $30^{\circ} \mathrm{C}$ in an evaporator (Büchi, Flawil, Switzerland) and the dry weight was determined for each extract.

Toxicity bioassay. The bioassay was conducted according to Dor et al. (3) on germinating Phelipanche seed. Briefly, 45-mmdiameter petri dishes were used, into which 7-mm-diameter GF/A glass microfiber filter paper disks (Whatman International) were placed on top of two layers of filter paper. Surface-sterilized $P$. aegyptiaca seed were distributed evenly on the disks at a density of 50 seeds/disk and the petri dishes were kept at $25^{\circ} \mathrm{C}$ for 1 week; then $250 \mu \mathrm{l}(5 \mathrm{ppm})$ of the synthetic stimulant GR24 was added. Four days later, two disks carrying seed were gently blotted on sterile filter paper and transferred to new petri dishes, which were fitted with strips of sterile moistened filter paper around the inner walls to maintain high humidity in the dishes during the test. A $12-\mu \mathrm{l}$ aliquot of $2 \%$ ethanol solution containing $200 \mu \mathrm{g}$ of the extract was gently applied to each paper disk, while the same ethanol solution without extract was used as a control. The plates were kept at $25^{\circ} \mathrm{C}$ for $48 \mathrm{~h}$. P. aegyptiaca seed germination was observed under a stereoscopic microscope, and seedling mortality was calculated for each extract.

$S L-O R T 1$ and M-82 grown together in the same pot. Tomato plants were grown under greenhouse conditions in 2-liter pots according to the following scheme (Fig. 1): A, one M-82 plant surrounded by four M-82 plants; B, one M-82 plant surrounded by four $S L-O R T 1$ plants; C, one $S L-O R T 1$ plant surrounded by four $S L-O R T 1$ plants; and D, one $S L-O R T 1$ plant surrounded by four M-82 plants. The distance between each plant was $5 \mathrm{~cm}$. Each treatment included six pots (replicates). The soil in the pots was artificially infested with $P$. aegyptiaca seed $(15 \mathrm{ppm})$ as described. At the end of the experiment, the soil from each pot was gently removed from the roots under running tap water, the root system of each plant was separated, and the number of broomrape species on each plant was recorded.

Paper bag experiments testing response of Orobanche seed germination to plant stimulants. The following three experiments were conducted to determine whether the mechanism of resistance in $S L-O R T 1$ is (i) lack of stimulant synthesis or secretion, (ii) release of a stimulant antagonist, or (iii) release of substances that affect broomrape germ tube or retard broomrape attachment. Each possibility was investigated in a separate experiment. In all of these bag experiments, paper bags containing $P$. aegyptiaca seed were placed among the tomato roots, allowing the roots to grow alongside or into them. The bags were either saturated with GR24 solution or not saturated. The seed bags were constructed as follows: $P$. aegyptiaca seed were distributed evenly on a square 5-by-5-cm GF/A paper ( $\approx 70$ seeds/ $\mathrm{cm}^{2}$ ). The paper carrying the seed was covered with an identical GF/A paper and the two pieces were stapled tightly together along the edges.

Ability of SL-ORT1 and M-82 to stimulate P. aegyptiaca seed germination. The ability of tomato plants to stimulate the germination of broomrape seed was examined by inserting the abovedescribed bags together with a tomato plant, adjoining the roots. Three bags were placed in each pot. The experiment was carried out under $14 \mathrm{~h}$ of natural daylight for 4 weeks. The experiment included $S L-O R T 1$ and M-82, and control pots with bags but without plants as a control for spontaneous $P$. aegyptiaca seed germination.

Each week, for a period of 3 weeks beginning 2 weeks after planting, the soil was rinsed from five pots and three control pots. The GF/A paper bags with the broomrape seed were gently washed with tap water and opened, and percentage seed germination was recorded with the aid of a stereoscopic microscope.

Ability of SL-ORT1 and M-82 to release active substances that retard stimulant activity. Paper bags were prepared with surface- 
sterilized $P$. aegyptiaca seed that had undergone preconditioning as already described previously. The bags were soaked with $500 \mu \mathrm{l}$ of the synthetic stimulant GR24 at a concentration of $3 \mathrm{ppm}$; bags soaked with $500 \mu \mathrm{l}$ of sterile water served as controls. The bags were immediately placed in pots as described for the first experiment. The experiment was carried out under $14 \mathrm{~h}$ of natural daylight for 14 days.

The paper bags containing the seed were removed from the pots 2 weeks after planting and the percentage of broomrape seed germination was determined under a stereoscopic microscope.

Ability of SL-ORT1 to secrete toxic substances which prevent growth or attachment of germinated P. aegyptiaca seed. Paper bags with preconditioned $P$. aegyptiaca seed (as described above) were soaked with $500 \mu \mathrm{l}(3 \mathrm{ppm})$ of GR24; paper bags with seed soaked in $500 \mu \mathrm{l}$ of sterile water served as controls. The bags were placed in the soil such that the SL-ORT1 or M-82 roots were stapled between the two layers of GF/A paper containing the $P$. aegyptiaca seed on their inner walls. The plants bearing the bags on their roots were planted in the pots with the bags placed $\approx 1$ to $3 \mathrm{~cm}$ below the soil surface.

Each pot was drenched with the synthetic stimulant GR24 (100 $\mathrm{ml}$ at a concentration of $3 \mathrm{ppm}$ ) on days 5 and 10 after planting. Control pots were similarly drenched with $100 \mathrm{ml}$ of water. The experiment was carried out under $14 \mathrm{~h}$ of natural daylight for 21 days. Three weeks after the start of the experiment, the paper bags containing the seed and the roots were removed from the pots and the percentage of germinated seed and $P$. aegyptiaca tubercles (small rounded attachments on the host roots) were counted under a stereoscopic microscope. The number of tubercles attached per $1 \mathrm{~cm}$ of root was calculated.

Chemical analysis of strigolactones in root exudates of $S L$ ORT1 and M-82 plants. Growth under hydroponic conditions. Sheets of rock wool ( 50 by 35 by $2 \mathrm{~cm}$ ) were thoroughly rinsed with water and sterilized at $121^{\circ} \mathrm{C}$ for $20 \mathrm{~min}$. The sheets were placed on a steel net on the top of black plastic containers ( 52 by 38 by $17 \mathrm{~cm}$ ) containing 18 liters of modified half-strength Hoagland's nutrient solution from which the phosphate source was omitted $\left(1.5 \mathrm{mM} \mathrm{Ca}\left(\mathrm{NO}_{3}\right)_{2}, 1.1 \mathrm{mM} \mathrm{MgSO}{ }_{4}, 2.5 \mathrm{mM} \mathrm{KCl}\right.$, $4.5 \mu \mathrm{m} \mathrm{MnCl}_{2}, 23 \mu \mathrm{M} \mathrm{H}_{3} \mathrm{BO}_{3}, 0.15 \mu \mathrm{M} \mathrm{CuSO}_{4}, 0.4 \mu \mathrm{M} \mathrm{ZnCl}$, $0.15 \mu \mathrm{M} \mathrm{Na}_{2} \mathrm{MoO}_{4}$, and $0.05 \mathrm{~g}$ of sequestrene) (41). The solution surface was at the same height as the bottom of the rock wool to keep it moistened.

Seed of SL-ORTland M-82 were surface sterilized in $70 \%$ ethanol for $0.5 \mathrm{~min}$ and then in $1 \%$ sodium hypochlorite containing $0.02 \%$ (vol/vol) Tween 20 for $2.5 \mathrm{~min}$. After thoroughly rinsing with sterile distilled water, the seed were sown on the moistened rock wool ( $\approx 500$ tomato seeds per container). Two containers were used for each line. The containers were placed in a growth room at $25^{\circ} \mathrm{C}$ under a photoperiod of $16 \mathrm{~h}$ of light and $8 \mathrm{~h}$ or darkness (16).

Root exudates. The solution in the container was circulated through sponge filters coupled with $50-\mu \mathrm{m}$ nylon net bags containing $5 \mathrm{~g}$ of activated charcoal powder (Finkelman, Petah Tikva, Israel) and was oxygenated with an aquarium pump. The nutrient solution and the charcoal bags were replaced twice a week. The charcoal in the two nylon bags that were collected each week was combined, washed with water, and extracted three times with equal volumes of acetone (SAR; Biolab Ltd.). The acetone solutions were combined and the acetone was evaporated under reduced pressure at $35^{\circ} \mathrm{C}$ (Rodovapor; Büchi). The residue was dissolved in $200 \mathrm{ml}$ of water and the solution was extracted three times with equal volumes of ethyl acetate. The ethyl acetate fractions were combined, washed with $0.2 \mathrm{M} \mathrm{K}_{2} \mathrm{HPO}_{4}(\mathrm{pH} 8.3)$, dried over anhydrous $\mathrm{Na}_{2} \mathrm{SO}_{4}$, and concentrated under reduced pressure at $35^{\circ} \mathrm{C}$. Dry extracts were stored at $4{ }^{\circ} \mathrm{C}$.

Root extracts. Tomato roots were homogenized in acetone (1:2, $\mathrm{wt} / \mathrm{vol}$ ) in a blender (Waring Commercial Products, Torrington, CT) at top speed for $1 \mathrm{~min}$. After filtration through Watman No. 3 filter paper, the acetone was evaporated under reduced pressure at $35^{\circ} \mathrm{C}$. The rest of the procedure was as described above. All extracts were tested for their ability to induce germination of $P$. aegyptiaca seed.

Extraction of soil solutes. Plants were grown in 10-liter pots with a faucet at the bottom, allowing the collection of excess solution from the pots. The bottom of the pot was filled with a $2-\mathrm{cm}$ layer of gravel and a mixture of sand and vermiculite $(1: 1$, $\mathrm{vol} / \mathrm{vol}$ ) above it. Twenty-five 2-week-old seedlings of SL-ORT1 and M-82 were taken from the hydroponic system and planted in the pots. Four pots were used for each treatment. The pots were placed in a growth chamber at $25^{\circ} \mathrm{C}$ under a photoperiod of 16 and $8 \mathrm{~h}$. The pots were irrigated with modified half-strength Hoagland solution (see hydroponics) twice a week for a total of 4 liters of fresh solution per week. After each irrigation, the excess solution in the pots was collected via the faucet on the bottom. The collected liquids, containing root exudates, were filtered through $2 \mathrm{~g}$ of activated charcoal. The charcoal was passed through no. 1 filter paper and then extracted as described above. At the end of the experiment (5 weeks), the roots were washed gently and extracted. All root exudates and extracts were tested for their ability to induce germination of $P$. aegyptiaca seed.

Germination assay. Preconditioned P. aegyptiaca seed were prepared as described previously. Methanol solution of the rootexudate samples in a concentration range of 0.05 to $10 \mathrm{ppm}$ was added to a 45-mm-diameter petri dish lined with a filter paper (41). The solvent was allowed to evaporate before the disks carrying the conditioned seed were placed on the filter paper and treated with $600 \mu \mathrm{l}$ of sterile distilled water. Four disks with preconditioned seed on them were dried gently on sterile filter paper and transferred to the petri dishes, which were sealed, wrapped with aluminum foil, and placed in the dark at $25^{\circ} \mathrm{C}$ for 4 to 5 days. Seed treated with or without GR24 at 3 ppm were always included as positive and negative controls, respectively.

Strigolactone analysis. Strigolactone analysis was performed according to Yoneyama et al. (41). Briefly, HPLC separation was conducted with a U980 HPLC instrument (Jasco, Tokyo) fitted with an ODS $\left(\mathrm{C}_{18}\right)$ column (Mightysil RP-18, 2 by $250 \mathrm{~mm}$, $5 \mu \mathrm{m}$; Kanto Chemicals). The mobile phase was $60 \%$ methanol in water (vol/vol) and was changed to $100 \%$ methanol 15 min after injection. The column was then washed with $100 \%$ methanol for $20 \mathrm{~min}$ at a flow rate of $0.2 \mathrm{ml} / \mathrm{min}$, and the column temperature was set to $40^{\circ} \mathrm{C}$.

Mass spectrometry was performed with a Quattro LC mass spectrometer (Micromass, Manchester, UK) equipped with an electrospray source. Nitrogen served as both the drying and nebulizing gas, generated from pressurized air in an N2G nitrogen generator (Parker-Hanifin Japan, Tokyo). The nebulizing gas flow was set to $\approx 100$ liter/h and the desolvation gas flow was set to 500 liters/h. The interface temperature was set to $400^{\circ} \mathrm{C}$ and the source temperature to $150^{\circ} \mathrm{C}$. The capillary and cone voltages were adjusted to orobanchol and to the positive ionization mode. Tandem mass spectrometry (MS/MS) experiments were conducted using argon as the collision gas and the collision energy was set to $16 \mathrm{eV}$. The collision gas pressure was $0.15 \mathrm{~Pa}$. The transition of $\mathrm{m} / \mathrm{z}, 369>272$ was monitored for orobanchol, $\mathrm{m} / \mathrm{z}$ $367>270$ for didehydro-orobanchol, and $m / z 365>268$ for solanacol. Data acquisition and analysis were performed with MassLynx software (version 3.2). Orobanchol and solanacol were quantified by using pure standards. The root-extract sample was dissolved in $50 \%$ aqueous methanol and filtered through a spin column (Ultra-free MC, $0.45-\mu \mathrm{m}$ pore size; Millipore). An aliquot of the filtered solution was diluted with a volume of either pure $50 \%$ methanol or $50 \%$ methanol containing known amounts of orobanchol and solanacol. The increase in peak area on the chromatogram corresponded to the amount of orobanchol or solanacol added, enabling estimation of the amount of orobanchol 
and solanacol in the sample. The identity of didehydro-orobanchol was not verified using a standard. Determination of this compound was based on the transition of $\mathrm{m} / \mathrm{z} 367>270$ and retention time. All peaks corresponding to strigolactones were confirmed by $P$. aegyptiaca seed-germination assay.

Statistical analysis. Data were subjected to analysis of variance (ANOVA) using JMP Software (version 5.0; SAS Institute Inc., Cary, NC). All quantitative data on broomrape germination before ANOVA were transformed to $\log _{10} x$, where $x$ is the original result. On the figures, back-transformed means are presented. The means of broomrape germination were separated by the standard error of the means. Means of broomrape number in the simultaneous growth experiment were compared by leastsignificant differences based on the Tukey-Kramer honestly significant difference test $(P=0.05)$. Each experiment was conducted twice. There were no significant differences between the repeated experiments; therefore, all analyses were performed on data averaged over the two experiments, except the liquid chromatography (LC)-MS/MS analysis data, which represented a single typical experiment.

\section{RESULTS}

Search for possible toxic activity of root extracts on $\boldsymbol{P}$. aegyptiaca seed germination. The presence of toxic metabolites in SL-ORT1 and M-82 roots was assayed by exposing germinating $P$. aegyptiaca seed to the root extracts of both varieties. Weak toxicity was found in the methanol extracts taken from broomrape-infected $(\approx 30 \%$ mortality) and noninfected $(\approx 10 \%$ mortality) tomato roots. In neither case were there any differences in mortality rate between $\mathrm{M}-82$ and $S L-O R T 1$ root extracts (data not shown).

The hexane, chloroform, ethyl acetate, methanol, and water extracts did not demonstrate any toxic activity on $P$. aegyptiaca seed germination. The extracts applied to preconditioned seed did not increase seed mortality, which was similar to the 3 to $5 \%$ mortality in the control.

$S L-O R T 1$ and M-82 grown together in the same pot. This experiment was conducted to investigate and compare the influence of SL-ORT1 and M-82 roots on broomrape parasitism.
In all, $\approx 15$ broomrape plants were attached to the root system of each M-82 tomato plant grown in broomrape-infested soil in pots containing five M-82 plants (Fig. 2). Almost no attachments (an average of 0.15 tubercles/plant) could be found in the pots containing five $S L-O R T 1$ plants. However, when an SL-ORT1 plant was grown with four M-82 plants in the same pot, it lost its resistance: an average of five broomrape plants developed on the root system of the single $S L-O R T 1$ plant in the pot. At the same time, four $S L-O R T 1$ plants grown in the same pot with a single M-82 plant did not reduce the number of parasites attached to the single M-82 plant, indicating the absence of toxic compounds secreted by $S L-O R T 1$ roots.

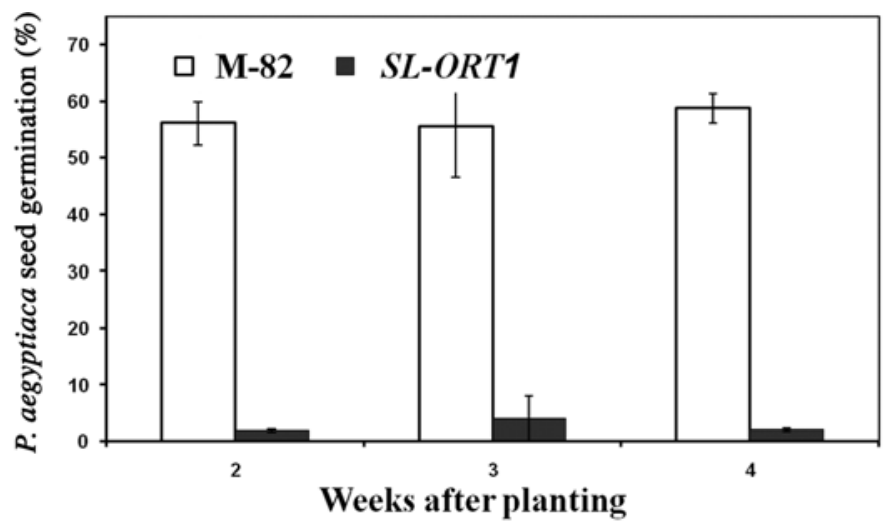

Fig. 3. Phelipanche aegyptiaca seed germination in the vicinity of M-82 and SL-ORT1 root systems. GF/A paper bags containing broomrape seed were planted adjoining the tomato roots. The experiment included SL-ORT1 and M82 , and pots with bags but without plants served as a control for spontaneous $P$. aegyptiaca seed germination. Beginning 2 weeks after planting, percentage of seed germination was recorded from five pots and three control pots with the aid of a stereoscopic microscope each week for a period of 3 weeks. Results were subjected to analysis of variance (ANOVA). Data are the average of two independent experiments. To meet the assumption on ANOVA, the quantitative data before ANOVA analysis were transformed to $\log _{10} x$, where $x$ is the original result. On the figure, back-transformed means are presented. Means of broomrape germination were separated by standard errors of the means, indicated by vertical lines on the bars. In the control pots, there was no spontaneous seed germination.

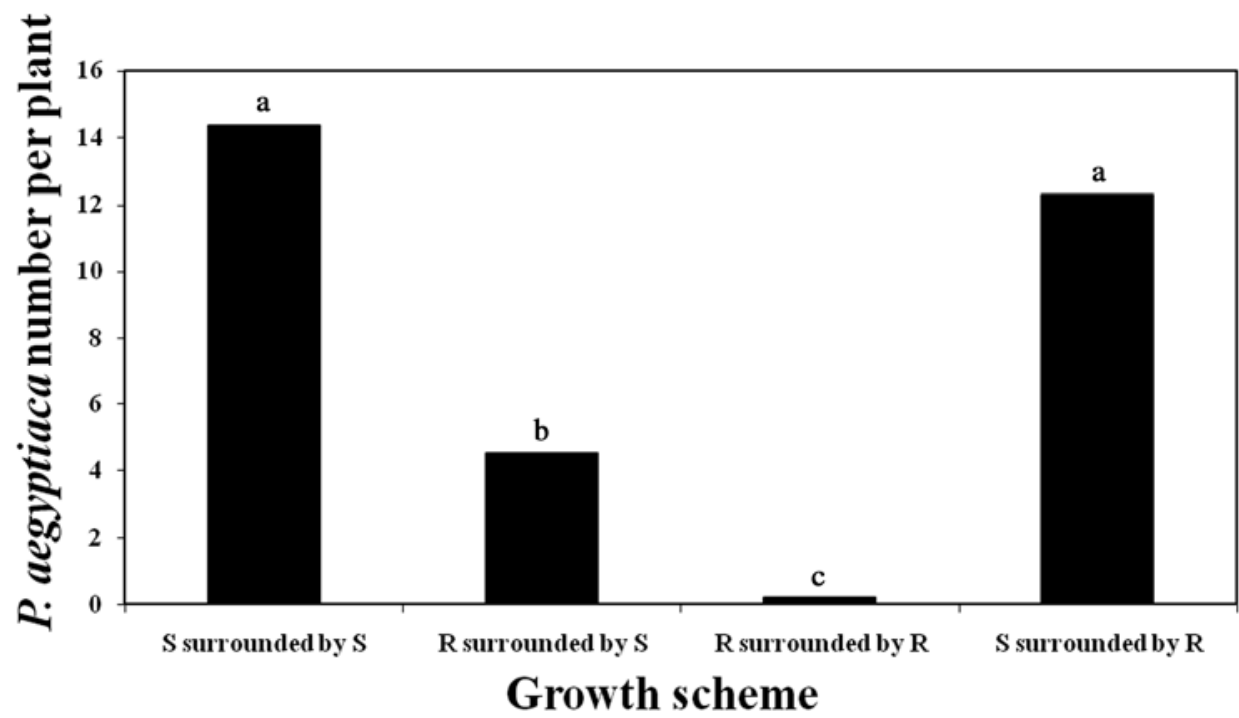

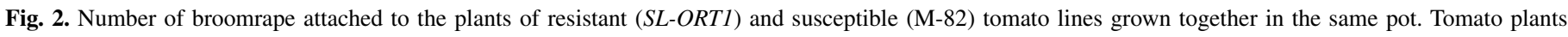

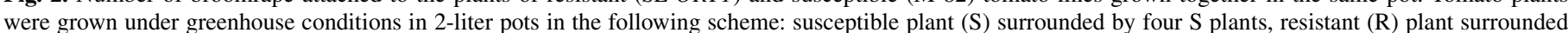

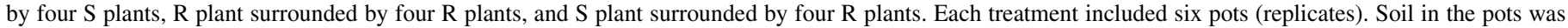

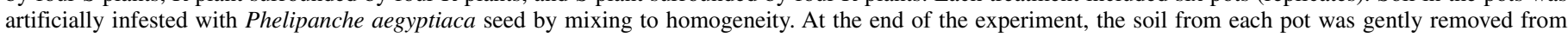

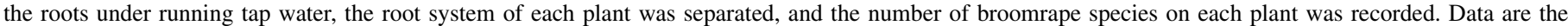

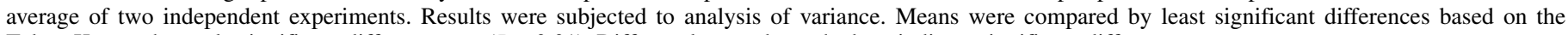
Tukey-Kramer honestly significant difference test $(P=0.01)$. Different letters above the bars indicate significant differences. 
Orobanche seed germination response to stimulants: paper bag experiment. Ability of $S L-O R T 1$ and $M-82$ to stimulate $P$. aegyptiaca seed germination. $P$. aegyptiaca seed germination in bags buried near $M-82$ roots was $\approx 60 \%$. In contrast, germination of their counterparts placed near SL-ORT1 roots was low, not exceeding 4\%, even 3 weeks after planting (Fig. 3). No spontaneous $P$. aegyptiaca seed germination was observed in the bags buried in the soil of control pots without tomato plants.

Ability of SL-ORT1 and M-82 to release active substances that retard stimulant activity. To examine the extent to which the root systems of SL-ORT1 and M-82 stimulate the germination of $P$. aegyptiaca seed, we buried them, in GF/A bags, near the plant roots. Whereas seed germination was $\approx 76 \%$ near $\mathrm{M}-82$ roots, germination near SL-ORT1 was negligible (0.7\%) (Table 1). When the parasite seed were pretreated with GR24 before burial in the soil, they reached $\approx 85 \%$ germination near both M-82 and $S L-O R T 1$ roots. In the control pots with no tomato plants, $P$. aegyptiaca seed did not germinate at all.

Ability of SL-ORT1 to secrete toxic substances which prevent the attachment of germinated $P$. aegyptiaca seed. $P$. aegyptiaca seed germinated only in the presence of M-82 roots, while negligible germination was observed in the presence of $S L-O R T 1$ roots. When GR24 was applied to the seed prior to burying them in the pots, in the presence of $S L-O R T 1$, the average germination rate was slightly higher than with $\mathrm{M}-82$ roots (Table 2 ).

Accordingly, although many parasite tubercles developed on M-82 roots with or without the addition of GR24, P. aegyptiaca tubercles developed on $S L-O R T 1$ roots only when the parasite seed were pretreated with the germination stimulant GR24 (Table 2; Fig. 4).

Germination bioassay of root exudates. This experiment was conducted to investigate the ability of M-82 and SL-ORT1 root exudates to induce broomrape seed germination. The root exudates of M-82 tomato plants grown hydroponically stimulated $P$. aegyptiaca seed germination at $0.05 \mathrm{ppm}$, the lowest concentration tested (Fig. 5A). This germination rate did not change significantly during the 5 weeks of the experiment, with a peak in week 4. $P$. aegyptiaca germination rates after treatment with GR24 at 3 ppm (positive control) or water (negative control) were 78 and $3 \%$, respectively.

$S L-O R T 1$ root exudates at a concentration of $0.05 \mathrm{ppm}$ did not stimulate $P$. aegyptiaca seed germination (Fig. 5A). Only at a concentration of $10 \mathrm{ppm}$ did the exudates cause significant $P$. aegyptiaca seed germination which, during the first 3 weeks, was lower than the germination caused by M-82 exudates: the same level of germination was only reached in weeks 4 and 5 (Fig. 5B).

Germination bioassay of root extracts. M-82 and SL-ORT1 root extracts at a concentration of $10 \mathrm{ppm}$ induced high germination rates of $P$. aegyptiaca seed (Fig. 6). However, similar to the exudates, low concentrations of the SL-ORT1 root extract did not induce seed germination at all, in contrast to the fairly high germination rates induced by the low concentration of M-82 extract.

Similar results were obtained with both exudates and extracts obtained from M-82 and SL-ORT1 roots grown in soil (data not shown). In this case, both M-82 root exudates and extracts at

TABLE 1. Germination percentage of Phelipanche aegyptiaca seed pretreated or not treated with the synthetic germination stimulant GR24, in GF/A glass microfiber paper bags buried near M-82 or $S L-O R T 1$ roots in the soil ${ }^{\mathrm{a}}$

\begin{tabular}{lcc}
\hline Tomato line & GR24 application & Germination $(\%)$ \\
\hline M-82 & - & $84.4 \pm 6.6$ \\
M-82 & + & $75.5 \pm 3.6$ \\
SL-ORT1 & - & $0.7 \pm 0.1$ \\
SL-ORT1 & + & $85.1 \pm 5.6$ \\
No plant (control) & - & 0 \\
\hline
\end{tabular}

${ }^{\text {a }}$ Data are the average of two independent experiments. concentrations of $0.05 \mathrm{ppm}$ caused $\approx 40 \%$ seed germination, whereas both exudates and extracts of $S L-O R T 1$ roots at the same concentration could not stimulate any seed germination. At $10 \mathrm{ppm}, \mathrm{M}-82$ root exudates and extracts induced $\approx 55 \%$ germination, whereas the germination induced by $S L-O R T 1$ root exudates and extracts fluctuated between 35 and $45 \%$.

LC-MS/MS analysis of root exudates of SL-ORT1 and M82. Three peaks corresponding to strigolactones were detected by LC-MS/MS analysis of M-82 root exudates (Fig. 7A). Orobanchol, in the transition $m / z, 369>272$, was detected at a retention time of $7.93 \mathrm{~min}$ as an intense peak. The MS/MS analysis and addition of orobanchol as an internal standard, as well as $P$. aegyptiaca seed-germination bioassay, confirmed its identity as orobanchol. Orobanchol level in M-82 root exudates in the first week of growth in the hydroponic system was $\approx 200 \mathrm{ng} / \mathrm{sample}$ (the amount produced by 1,000 plants grown hydroponically for 1 week) and, after 4 weeks, exceeded 2,000 ng (Fig. 8). In plants grown in the soil mixture, the highest orobanchol level was detected in root exudates after 2 weeks of growth; then, it decreased in weeks 3 and 4 and could not be detected in week 5 of growth.

Solanacol, detected in the transition $\mathrm{m} / \mathrm{z} 365>268$ with a retention time of $5.60 \mathrm{~min}$, was more intense than orobanchol. The MS/MS analysis and the addition of solanacol as an internal standard, together with the $P$. aegyptiaca seed-germination bioassay, confirmed its identity as solanacol. Solanacol in root exudates of M-82 in the hydroponic system after 3 and 5 weeks reached $\approx 6,000 \mathrm{ng} / \mathrm{sample}$ (Fig. 8). In the soil, the concentration of solanacol in root exudates of M-82 increased gradually, reaching $90 \mathrm{ng} / \mathrm{sample}$ at the end of the experiment.

The third peak corresponded to putative didehydro-orobanchol isomers and was detected in the transition $\mathrm{m} / \mathrm{z} 367>270$ with a retention time of $6.60 \mathrm{~min}$. The identity of this compound was not verified using a standard (because it is unavailable) but was confirmed by MS/MS analysis and broomrape seed-germination bioassay. The amount of didehydro-orobanchol in root exudates of M-82 plants grown hydroponically peaked after 3 weeks and reached a maximum level after 5 weeks. In the soil, like solanacol, it increased with time, reaching its highest level after 5 weeks.

All three strigolactones were at insignificant or undetectable levels in the exudates of SL-ORT1 plants (Fig. 7B) grown both hydroponically and in the soil, except solanacol in soil exudates after 2 weeks of growth (Fig. 8). The absence of strigolactones in the root exudates was confirmed by broomrape seed-germination bioassay.

LC-MS/MS analysis of root extracts of $S L-O R T 1$ and M-82. M-82 root extracts exhibited three peaks corresponding with the above-described strigolactones (16). Orobanchol was present in M-82 roots at concentrations of 0.76 and $0.37 \mathrm{ng} / \mathrm{g}$ root when grown hydroponically and in the soil, respectively (Table 3 ). The peak corresponding to solanacol in the hydroponic system was more intense than that of orobanchol. The concentration of solanacol was $\approx 6.76 \mathrm{ng} / \mathrm{g}$ of root. In the soil, its concentration was lower than that of orobanchol, $0.19 \mathrm{ng} / \mathrm{g}$ of root. The third peak

TABLE 2. Phelipanche aegyptiaca seed germination rate and number of attached broomrape on M-82 or SL-ORT1 roots within GF/A paper bags buried in the soil ${ }^{\mathrm{a}}$

\begin{tabular}{lccc}
\hline Tomato line & $\begin{array}{c}\text { GR24 } \\
\text { application }\end{array}$ & $\begin{array}{c}\text { Germination } \\
(\%)\end{array}$ & $\begin{array}{c}\text { Tubercles } \\
\text { (per 1 cm of root) }\end{array}$ \\
\hline M-82 & - & $64.9 \pm 4.3$ & $1.95 \pm 0.51$ \\
M-82 & + & $76.9 \pm 2.4$ & $1.88 \pm 0.35$ \\
SL-ORT1 & - & $0.7 \pm 0.2$ & $0.10 \pm 0.03$ \\
SL-ORT1 & + & $81.4 \pm 1.2$ & $1.00 \pm 0.18$ \\
No plant (control) & - & 0 & 0 \\
\hline
\end{tabular}

a Data are the average of two independent experiments. 
corresponded to putative didehydro-orobanchol isomers. The peak area of this compound in M-82 root extract was 13048 and 123 in plants grown hydroponically and in the soil, respectively.

In the root extract of $S L-O R T 1$ plants grown hydroponically, only solanacol and didehydro-orobanchol isomers were detected (Table 3). The concentration of solanacol was $\approx 0.61 \mathrm{ng} / \mathrm{g}$ of root. The didehydro-orobanchol isomers peak was less intense than in the M-82 root extract. Peak area of this compound in the $S L$ ORT1 root extract was 408. No solanacol or didehydroorobanchol could be detected in the roots of $S L-O R T 1$ plants grown in soil.

Orobanchol was not detected in the root extracts of SL-ORT1, regardless of the growth system.

\section{DISCUSSION}

The $S L-O R T 1$ tomato mutant exhibits high resistance to several broomrape species (2). Our results implicate a resistance mechanism that is active before the establishment of a physical connection between the parasite and the tomato root. Observations of $S L$ ORT1 roots grown in broomrape-infested soil revealed normal root-system development in terms of biomass and architecture, comparable with that of M-82 (2).

Toxic substances secreted from or present within the roots (phytoalexins or phytotoxins) have been proposed as resistance mechanisms in other plants (e.g., Medicago truncatula) (21), sunflower (5,33), Arabidopsis (7), carrot (43), vetch $(10,25,27)$, faba bean (42), and chickpea (29). The release of toxic substances that kill or hinder haustorial cell development have also been noted in sorghum-Striga spp. associations (22). These documented cases of early resistance responses are consistently associated with browning symptoms of both parasite and hostroot tissues (5), or with reduced germination rates and browning of the radicles of germinated broomrape seed (33). In contrast, in the $S L-O R T 1$ tomato mutant, there is no indication of any stress or hypersensitive response. Instead, once a parasite attachment is formed, parasite development progresses to maturity without any abnormal signs (2). To further exclude the involvement of toxic metabolites in $S L-O R T 1$ roots, we used large amounts of $S L$ ORT1 root extract in a $P$. aegyptiaca seed-germination bioassay and, indeed, we found no toxic effects. Furthermore, growing resistant $S L-O R T 1$ plants together with the susceptible M-82 plants in the same pot changed the resistant phenotype into a sensitive one but not vice versa, supporting the assumption that no toxic metabolites are secreted by the roots of the resistant plants (Fig. 2).
$P$. aegyptiaca seed packed in paper bags and placed in the rhizosphere of $S L-O R T 1$ roots did not germinate, in contrast to $60 \%$ germination of $P$. aegyptiaca seed placed in the rhizosphere of M-82 roots (Fig. 3). These results suggested that SL-ORT1
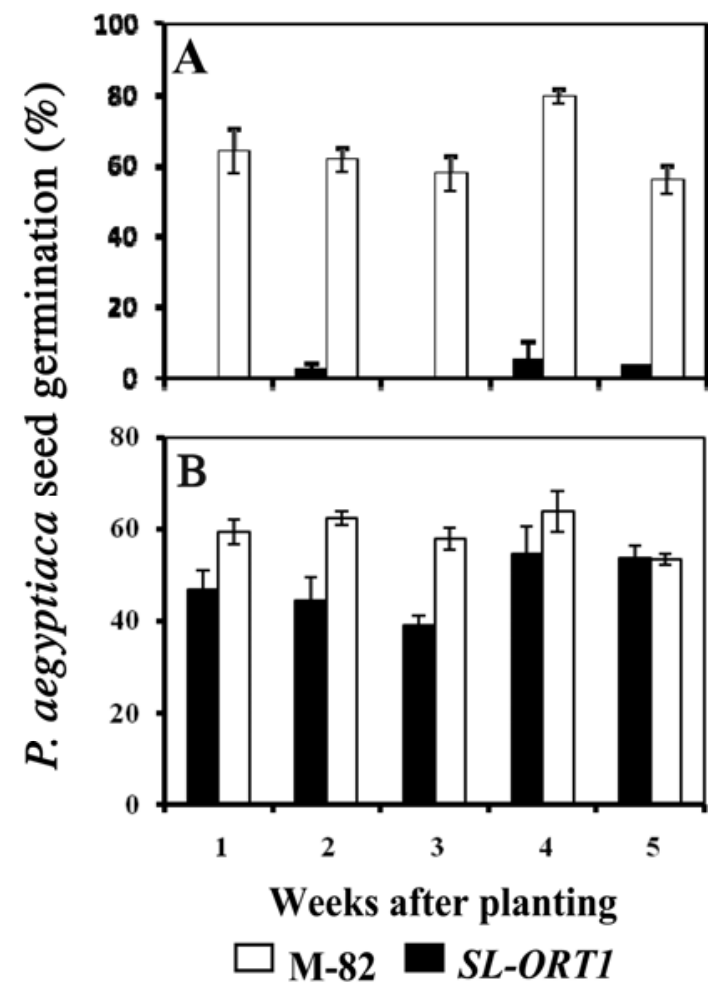

Fig. 5. Phelipanche aegyptiaca seed germination induced by root exudates of susceptible (M-82) and resistant (SL-ORT1) tomato lines. A, Root exudates at a concentration of $0.05 \mathrm{ppm}$. B, Root exudates at $10 \mathrm{ppm}$. A methanol solution of the root exudates was added to a 45-mm-diameter petri dish. Discs carrying the conditioned $P$. aegyptiaca seed were added and treated with $600 \mu \mathrm{l}$ of sterile distilled water. The petri dishes were sealed, wrapped with aluminum foil, and placed in the dark at $25^{\circ} \mathrm{C}$ for 4 to 5 days. Seed treated with or without GR24 at 3 ppm were always included as positive and negative controls, respectively. Results were subjected to analysis of variance (ANOVA). Data are the average of two independent experiments. To meet the assumption on ANOVA, the quantitative data before ANOVA analysis were transformed to $\log _{10} x$, where $x$ is the original result. On the figure, back-transformed means are presented. Means of broomrape mortality were separated by standard errors of the means, indicated by vertical lines on the bars.
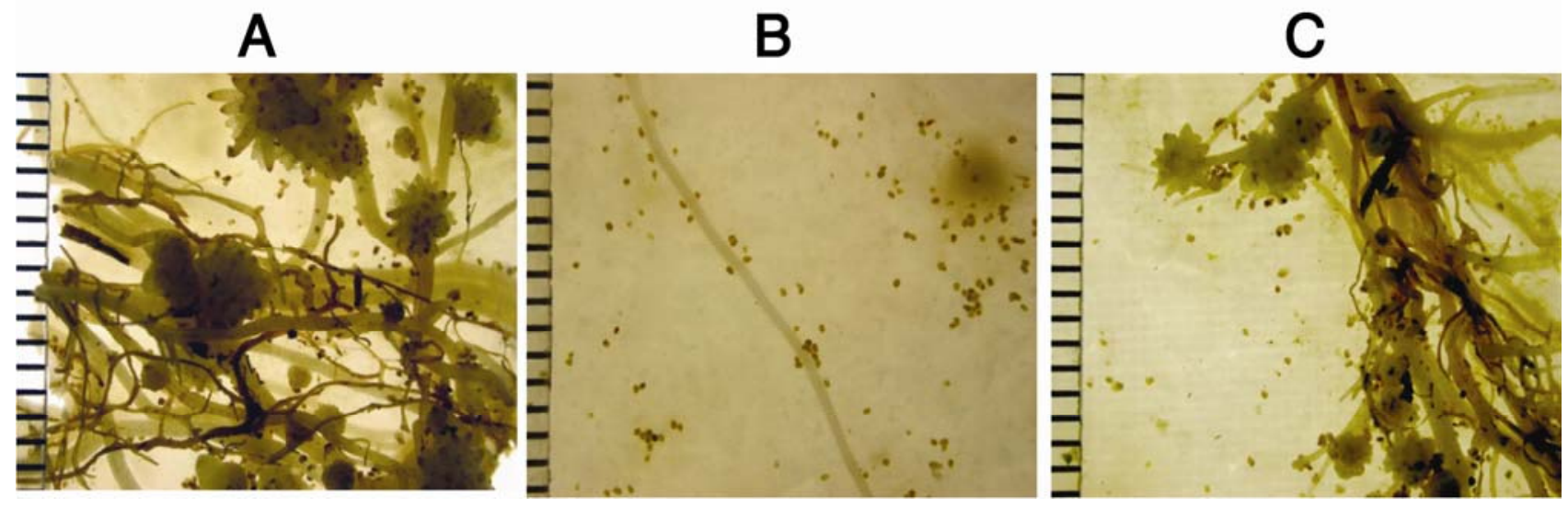

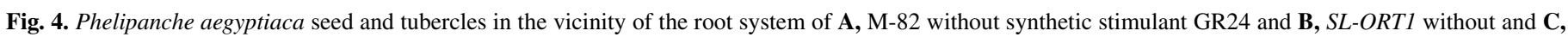

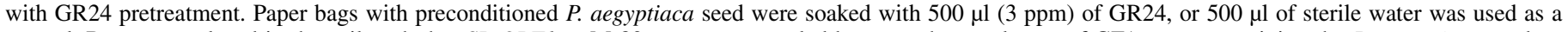

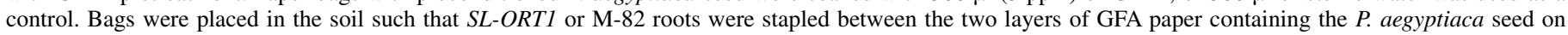

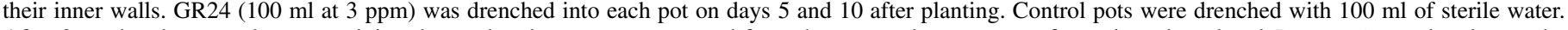

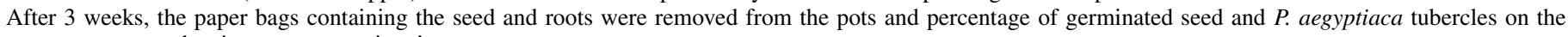
roots were counted, using a stereoscopic microscope. 
roots release substances that retard stimulant activity. However, this assumption was rejected by repeating the experiment with $P$. aegyptiaca seed which had been pretreated with the synthetic germination stimulant GR24. The $P$. aegyptiaca seed were expected to respond to the presence of GR24 and germinate only if no interfering metabolites were released by $S L-O R T 1$ roots. The results, showing similar germination rates of $P$. aegyptiaca seed near both $S L-O R T 1$ and M-82 roots, clearly indicated that there is no inhibition of stimulant activity.

Another possible reason for preattachment resistance is prevention of parasite attachment to the host root. However, SLORT1 roots allowed the development of normal tubercles when the parasite seed were pregerminated with the germination stimulant GR24.

Nevertheless, the results in both experiments clearly indicated $S L$-ORTI's inability to induce $P$. aegyptiaca seed germination, reflected in the low susceptibility of this mutant to the parasite. Only a negligible number of parasite tubercles were found on $S L$ ORT1 roots, compared with $\approx 2$ tubercles per $1 \mathrm{~cm}$ of root in M-82 plants. However, SL-ORT1 roots allowed the development of normal tubercles when the parasite seed were pregerminated with the germination stimulant GR24. The somewhat lower tubercle number attached per $1 \mathrm{~cm}$ of $S L-O R T 1$ root after artificially stimulating germination of the parasite seed, compared with M82 , may result from the lack of a stimulant gradient, which is believed to be responsible for the directional growth of the parasite toward the host root (35). In the absence of a stimulant gradient, the probability of a broomrape radicle meeting a tomato root depends only on the relative densities of the germinating seed

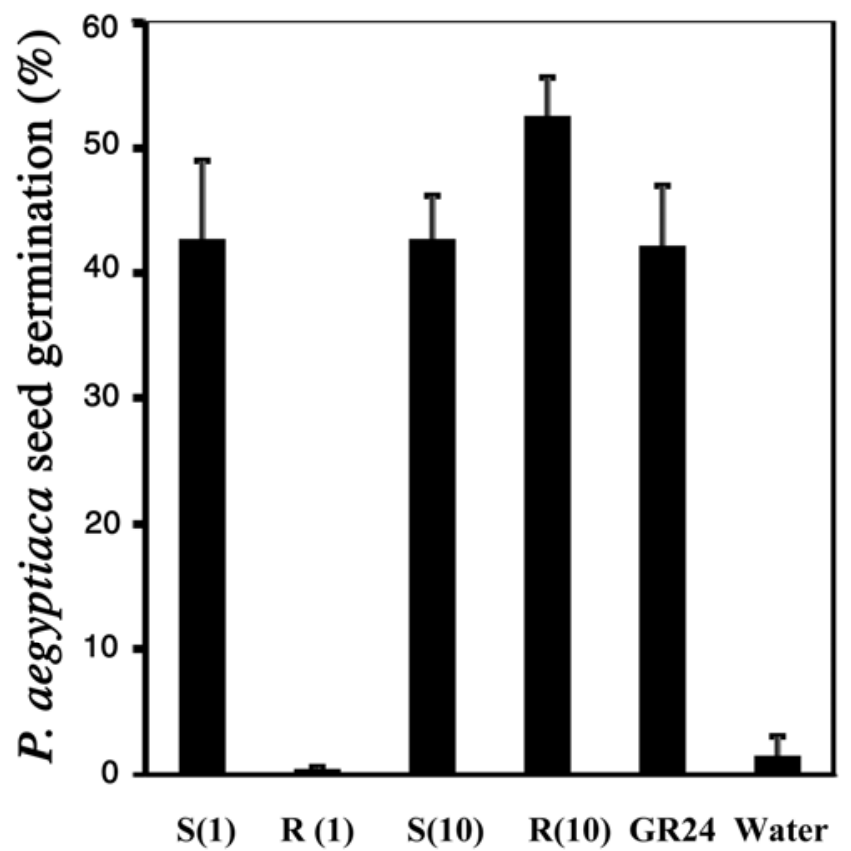

Fig. 6. Germination of Phelipanche aegyptiaca seed induced by root extracts of sensitive (M-82) and resistant $(S L-O R T 1)$ tomato lines. $\mathrm{S}(1)$ and $\mathrm{S}(10)=$ root exudates of M-82 at concentrations of 1 and $10 \mathrm{ppm}$, respectively; $\mathrm{R}(1)$ and $\mathrm{R}(10)=$ root exudates of SL-ORT1 at concentrations of 1 and $10 \mathrm{ppm}$, respectively. A methanol solution of the root extract was added to a $45-\mathrm{mm}$ diameter petri dish. Solvent was allowed to evaporate before the disks carrying the conditioned $P$. aegyptiaca seed were placed on the filter paper and treated with $600 \mu \mathrm{l}$ of sterile distilled water. Petri dishes were sealed, wrapped with aluminum foil, and placed in the dark at $25^{\circ} \mathrm{C}$ for 4 to 5 days. Seed treated with or without GR24 at 3 ppm were always included as positive and negative controls, respectively. Results were subjected to analysis of variance (ANOVA). Data are the average of two independent experiments. To meet the assumption on ANOVA, the quantitative data before ANOVA analysis were transformed to $\log _{10} x$, where $x$ is the original result. On the figure, backtransformed means are presented. The means of broomrape mortality were separated by the standard errors of the means, indicated by vertical bars. and of the host roots. In the case of M-82 roots, it is likely that directional growth of the parasite along the stimulant concentration gradient in the rhizosphere increases this probability.

To further support our conclusion that $S L-O R T 1$ plants lack the ability to stimulate germination of the parasite seed, we conducted analyses of root exudates and extracts of both SL-ORTI and M-82, grown hydroponically and in soil. Root exudates of $S L$-ORT1 plants that were grown hydroponically were unable to induce significant $P$. aegyptiaca seed germination during the 5 weeks of the experiment, whereas similar exudates from M-82 at the same concentration induced 60 to $80 \%$ seed germination, the same as GR24. This was true for exudates at a concentration of $0.05 \mathrm{ppm}$. The root exudates of SL-ORT1 stimulated 35 to $55 \%$ seed germination only when the concentration was raised 200fold (i.e., to $10 \mathrm{ppm}$ ). To determine whether the lack of stimulant activity in the $S L$-ORT1 rhizosphere is due to low stimulant production in the root, or only to low release of the stimulants from the roots to the environment, we also tested the stimulatory ability of root extracts of the two tomato lines, and found that $S L$ ORT1 roots contain significantly lower concentrations of the stimulants than M-82 roots, meaning that the mutant roots are not able to produce these stimulants.

Similar results were obtained with the root exudates and extracts of M-82 and SL-ORT1 grown in soil. No data exist as to the fate of stimulants of parasite seed germination in this medium.

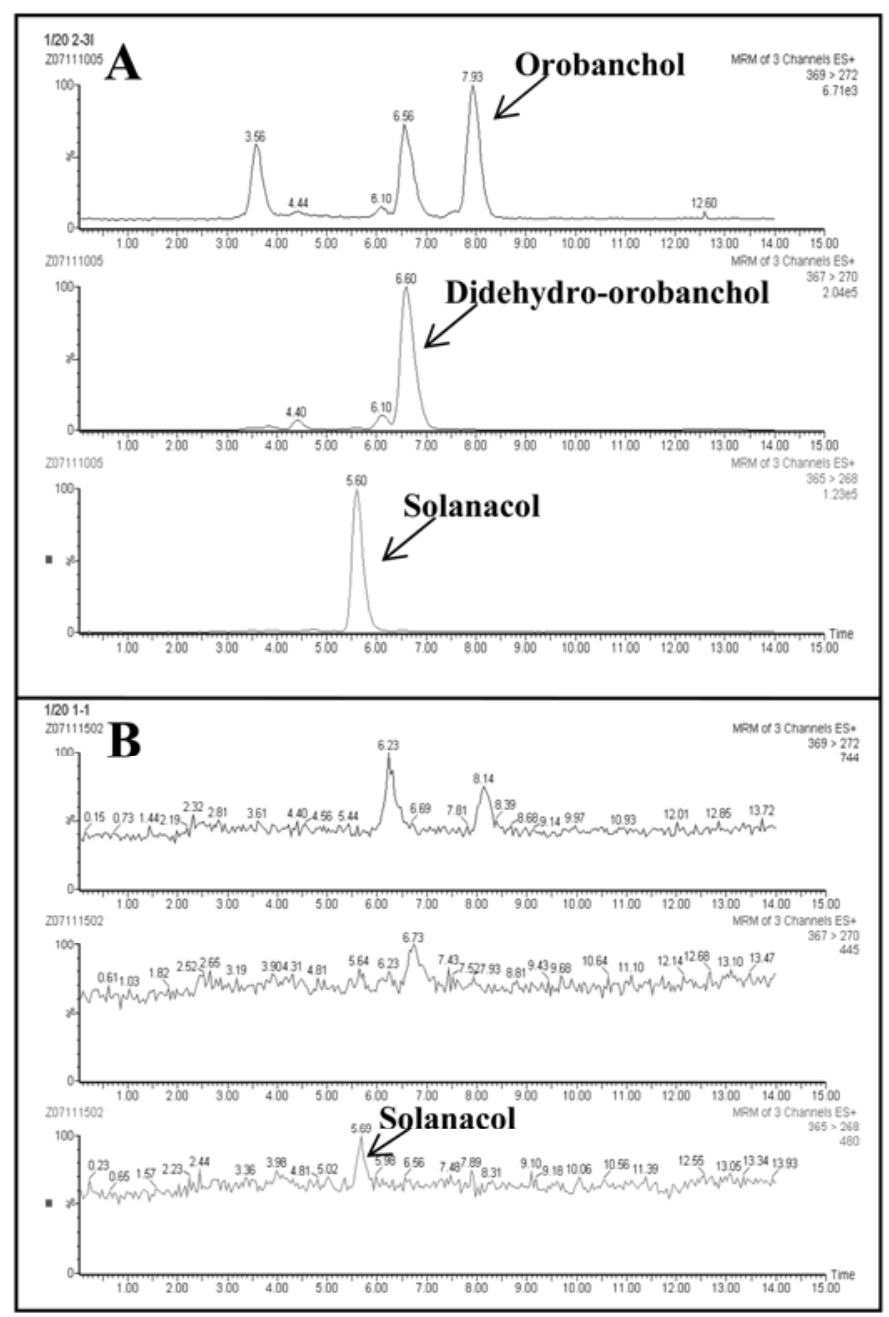

Fig. 7. Liquid chromatography tandem mass spectrometry analysis of $\mathbf{A}$, Phelipanche spp.-sensitive (M-82) and B, Phelipanche spp.-resistant ( $\mathrm{SL}$ ORT1) tomato lines' root exudates from plants grown in the hydroponic system. Chromatograms of transition $\mathrm{m} / z, 369>272$ for orobanchol, transition $\mathrm{m} / \mathrm{z}, 367>270$ for the didehydro-orobanchol isomers, and transition $\mathrm{m} / \mathrm{z} 365>$ 268 for solanacol. 
The differences in overall stimulant production and secretion between the two lines remained unchanged, regardless of the medium in which the roots were grown (i.e., liquid or solid). Note that we used a mixture of sand-vermiculite as the soil, which differs from normal soil mainly in its poor organic matter content and microbial activity, and the plants were furnished with phosphate-free nutrient solution in order to maximize strigolactone production $(20,39,41)$. We assume that different results would be obtained with authentic soil in the field, because organic matter, microbial activity, and contents of microelements such as phosphorus should have a dramatic influence on stimulant production and secretion.

The MS/MS analysis revealed that the determinate processing tomato var. M-82 produces three strigolactones: orobanchol, solanacoland didehydro-orobanchol isomers. The same three strigolactones have also been found in the root exudates of the indeterminate edible tomato var. Moneymaker (20). Orobanchol is probably the most abundant hydroxy-strigolactone in the plant kingdom (40), first isolated from red clover (Trifolium pretense L.) root exudates (36). Didehydro-orobanchol and solanacol, detected in the root exudates of tobacco (Nicotiana tabacum L.), are probably formed from oxidized orobanchol derivatives (40).

The relative amounts of the three strigolactones exuded by M-82 roots in the soil followed different kinetics than those from the hydroponic system. Orobanchol in the hydroponic system

TABLE 3. Strigolactone concentrations in Phelipanche aegyptiaca-sensitive (M-82) and -resistant (SL-ORT1) tomato root extracts grown hydroponically ${ }^{\mathrm{a}}$

\begin{tabular}{lccc}
\hline & \multicolumn{3}{c}{ Strigolactone concentration } \\
\cline { 2 - 4 } Tomato line & $\begin{array}{c}\text { Orobanchol } \\
\text { (ng/g root) }\end{array}$ & $\begin{array}{c}\text { Solanacol } \\
\text { (ng/g root) }\end{array}$ & $\begin{array}{c}\text { Didehydro-orobanchol } \\
\text { peak area }\end{array}$ \\
\hline Hydroponics & 0.76 & 6.76 & 13048 \\
M-82 & 0 & 0.61 & 408 \\
SL-ORT1 & 0.37 & 0.19 & 123 \\
Soil & 0 & 0 & 0 \\
M-82 & 0 & \\
SL-ORT1 & 0 & & \\
\hline
\end{tabular}

a All experiments were repeated at least twice and presented data are from a typical single experiment.

\section{$\mathbf{x 1 0}^{3}$ Hydroponics}
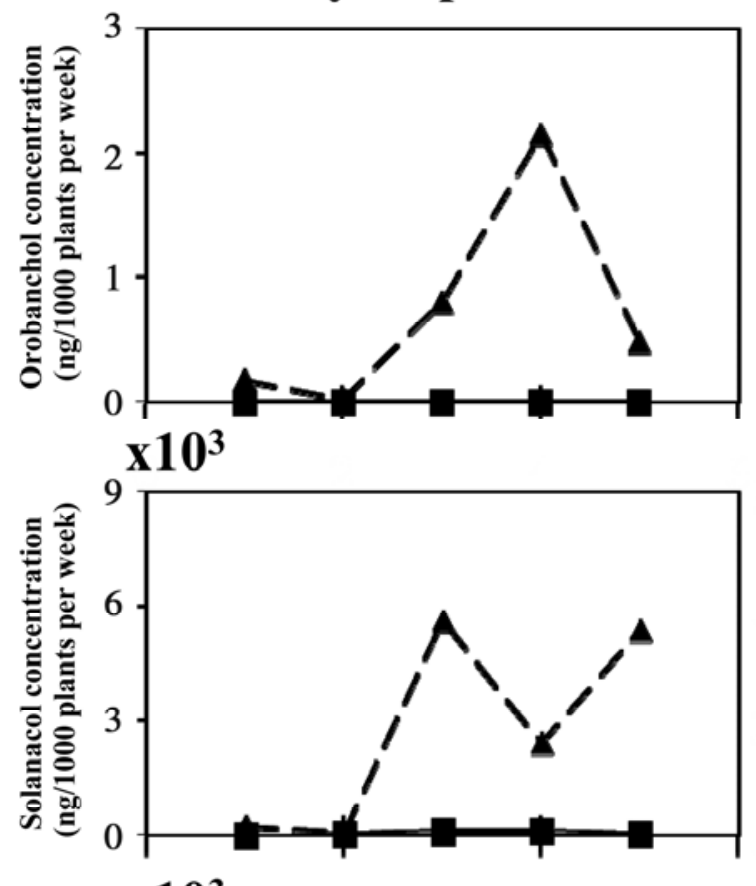

$\mathbf{x 1 0 ^ { 3 }}$

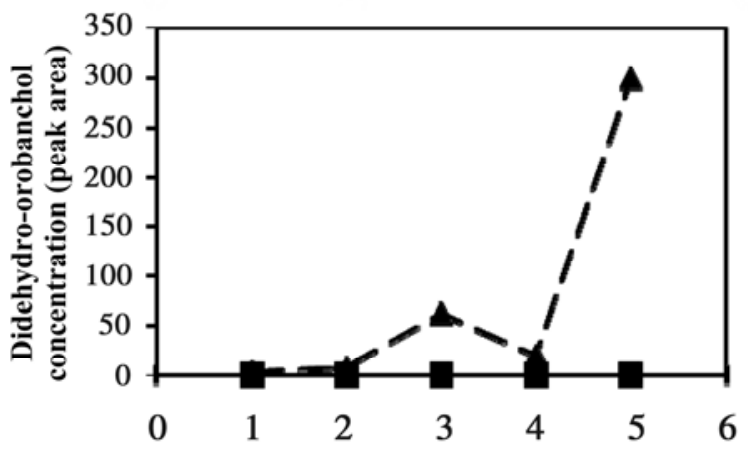

$\mathbf{x 1 0 ^ { 3 }} \quad$ Soil
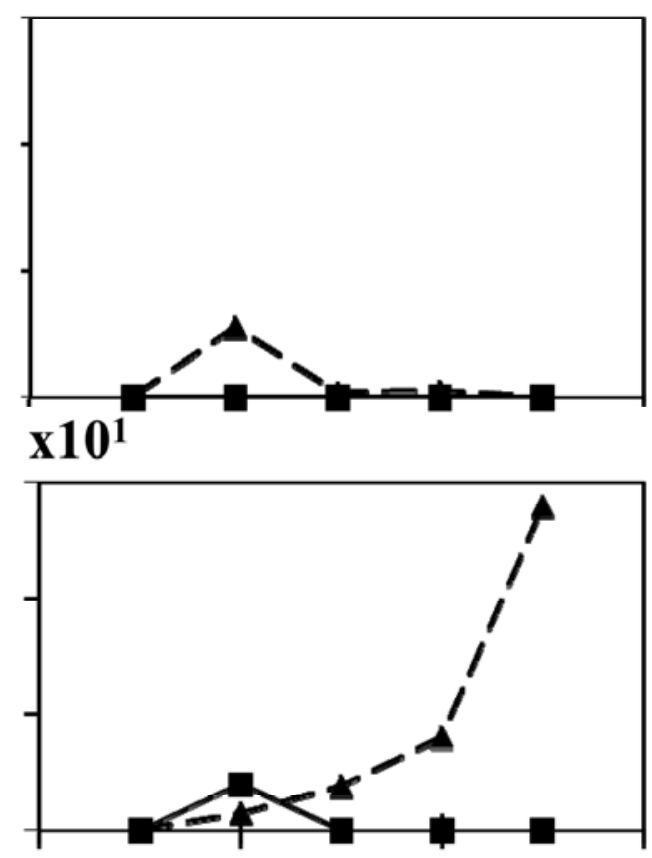

$\mathbf{x 1 0} 1$

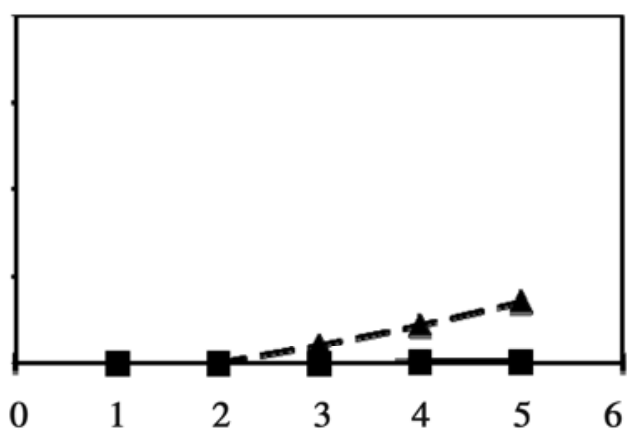

\section{- $\leftarrow$ - M-82 Weeks}

SL-ORT1

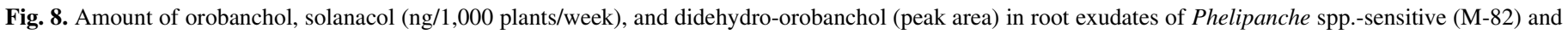

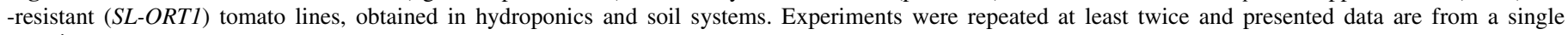
experiment. 
reached its maximum peak in week 4 and decreased to close to zero in the following week. In the soil, it peaked in week 2, decreasing to zero in the following weeks. Solanacol demonstrated two peak levels, in weeks 3 and 5, in the hydroponic system, while reaching its maximum amount in the soil in week 5. Didehydro-orobanchol was at its highest amount in week 5 under both growing systems. The differences in strigolactone secretion dynamics prove that no conclusions can be drawn on the behavior of strigolactone content in the soil from hydroponic systems. Organic matter, microbial activity, and contents of microelements may affect stimulant fate in the soil. To understand the interaction between strigolactones and broomrape seed in the field during the tomato-growing season, experiments should be performed in natural soil rather than in vitro. Each repetition in the hydroponic system consisted of 1,000 plants whereas, in the soil, there were 25 plants/pot. Standardization per plant is meaningless because the root volume or biomass per plant is unknown and, therefore, not comparable.

Phelipanche and Orobanche spp. demonstrate a high level of genetic flexibility and it is hypothesized that one resistance mechanism will be overcome in a relatively short time if used alone, as seen in sunflower, which is repeatedly attacked by newly developing races of $O$. cumana (8). However, combining several different resistance mechanisms (for example, low-germination stimulant production together with mechanical barriers, hypersensitive or incompatible responses in a single plant, or using the resistance mechanism of $S L-O R T 1$ in the context of an integrated management approach) may increase the ability to protect crop plants against the potential breakdown of resistance. Appropriate molecular markers of genetic populations may facilitate the transfer of resistance genes into tomato cultivars, as well as the combination of multiple resistance genes in agronomically desirable tomato cultivars, to produce highly broomrape-resistant tomato with outstanding agronomical performance. When the genetic mechanism of the resistance of SL-ORT1 is revealed and the encoding genes identified, it will be possible to produce additional broomrape-resistant crops utilizing the new methods of molecular biology.

\section{LITERATURE CITED}

1. Avdeyev, Y. I., Scherbinin, B. M., Ivanova, L. M., and Avdeyev A. Y. 2003. Studying of tomato resistance to broomrape and breeding varieties for processing. VIIIth International Symposium on the Processing Tomato. International Society for Horticultural Science. Acta Hortic. 613:283-290

2. Dor, E., Alperin, B., Wininger, S., Ben-Dor, B., Somvanshi, V. S., Koltai, H., Kapulnik, Y., and Hershenhorn, J. 2010. Characterization of a novel tomato mutant resistant to Orobanche and Phelipanche spp. weedy parasites. Euphytica 171:371-380.

3. Dor, E., Evidente, A., Amalfitano, C., Agrelli, D., and Hershenhorn, J. 2007. The influence of growth conditions on biomass, toxins and pathogenicity of Fusarium oxysporum f. sp. orthoceras, a potential agent for broomrape biocontrol. Weed Res. 47:345-352.

4. Dörr, I., Staack, A., and Kollmann, R. 1994. Resistance of Helianthus to Orobanche-histological and cytological studies. Pages 276-289 in: Biology and Management of Orobanche. Proc. Third Intl. Workshop on Orobanche and Related Striga Research. A. H. Pieterse, J. A. C. Verkleij, and S. J. ter Borg, eds. Amsterdam Royal Tropical Institute, Amsterdam.

5. Echevarría-Zomeño, S., Pérez-de-Luque, A., Jorrín, J., and Maldonado, A. M. 2006. Pre-haustorial resistance to broomrape (Orobanche cumana) in sunflower (Helianthus annuus): cytochemical studies. J. Exp. Bot. 57:4189-4200.

6. Ejeta, G., and Butler, L. G. 1993. Host-parasite interactions throughout the Striga life cycle and their contributions to Striga resistance. Afr. Crop Sci. J. 1:75-80.

7. El-Maarouf-Bouteau, H., Moreau, E., Errakhi, R., and Sallé, G. 2008. A diffusible signal from germinating Orobanche ramosa elicits early defense responses in suspension-cultured Arabidopsis thaliana. Plant Signal. Behav. 3:189-193.

8. Fernández-Martínez, J., Melero-Vara, J., Muñoz-Ruz, J., and Domíngues, J. 2000. Selection of wild and cultivated sunflower for resistance to a new broomrape race that overcomes resistance of the $\mathrm{Or}$ (5) gene. Crop Sci.
40:550-555.

9. Goldwasser, Y., Hershenhorn, J., Plakhine, D., Kleifeld, Y., and Rubin, B. 1999. Biochemical factors involved in vetch resistance to Orobanche aegyptiaca. Physiol. Mol. Plant. Pathol. 54:87-96.

10. Goldwasser, Y., Kleifeld, Y., Plakhine, D., and Rubin, B. 1997. Variation in vetch (Vicia spp.) response to Orobanche aegyptiaca. Weed Sci. 45:756-762.

11. Hershenhorn, J., Eizenberg, H., Dor, E., Kapulnik, Y., and Goldwasser, Y. 2009. Phelipanche aegyptiaca management in tomato. Weed Res. 49:3447.

12. Joel, D. M., Hershenhorn, J., Eizenberg, H., Aly, R., Ejeta, G., Rich, P. J., Ransom, J. K., Sauerborn, J., and Rubiales, D. 2007. Biology and management of weedy root parasites. Pages 267-349 in: Horticultural Reviews, Vol. 33. J. Janick, ed. John Wiley \& Sons, Hoboken, NJ.

13. Joel, D. M., and Portnoy, V. H. 1998. The angiospermous root parasite Orobanche L. (Orobanchaceae) induces expression of a pathogenesis related (PR) gene in susceptible tobacco roots. Ann. Bot. 81:779-781.

14. Joel, D. M., Steffens, J. C., and Matthews, D. E. 1995. Germination of weedy root parasites. Pages 567-598 in: Seed Development and Germination. J. Kigel, G. Galili, eds. Marcel Dekker, Inc., New York.

15. Jorrín, J., Pérez-de-Luque, A., and Serghini, K. 1999. How plants defend themselves against root parasitic angiosperms: molecular studies with Orobanche spp. Pages 9-15 in: Resistance to Orobanche: the State of the Art. J. I. Cubero, M. T, Moreno, D. Rubiales, and J. C. Sillero, eds. Publ. Junta de Andalucía, Sevilla, Spain.

16. Koltai, H., LekKala, S. P., Bahattacharya, C., Mayzlish-Gati, E., Resnick, N., Wininger, S., Dor, E., Yoneyama, K., Yoneyama, K., Hershenhorn, J., Joel, D. M., and Kapulnik, Y. 2010. A tomato strigolactone-impaired mutant displays aberrant shoot morphology and plant interactions. J. Exp. Bot. 61:1739-1749.

17. Labrousse, P., Arnaud, M. C., Griveau, Y., Fer, A., and Thalouran, P. 2004. Analysis of resistance criteria of sunflower recombined inbred lines against Orobanche cumana Wallr. Crop Prot. 23:407-413.

18. Labrousse, P., Arnaud, M. C., Seryes, H., Berville, A., and Thalouarn, P. 2001. Several mechanisms are involved in resistance of Helianthus to Orobanche cumana Wallr. Ann. Bot. 88:859-868.

19. Lejeune, A., Constant, S., Delavault, P., Simier, P., Thalouran, P., and Thoiron, P. 2006. Involvement of a putative Lycopersicon esculentum wall-associated kinase in the early steps of tomato-Orobanche ramosa interaction. Physiol. Mol. Plant Pathol. 69:3-12.

20. López-Ráez, J. A., Charnikhova, T., Gómez-Roldán, V., Matusova, R., Kohlen, W., De Vos, R., Verstappen, F., Puech-Pages, V., Bécard, G., Mulder, P., and Bouwmeester, H. 2008. Tomato strigolactones are derived from carotenoids and their biosynthesis is promoted by phosphate starvation. New Phytol. 178:863-874.

21. Lozano-Baena, M. D., Prats, E., Moreno, T. E., Rubiales, D., and Pérezde-Luque, A. 2007. Medicago truncatula as a model for nonhost resistance in legume-parasitic plant interactions. Plant Physiol. 145:437449.

22. Neumann, U., Vian, B., Weber, H. C., and Sallé, G. 1999. Interface between haustoria of parasitic members of the Scrophulariaceae and their hosts: a histochemical and immunocytological approach. Protoplasma 207:84-97.

23. Parker, C., and Riches, C. R. 1993. Parasitic Weeds of the World: Biology and Control. CAB International, Wallingford, UK.

24. Pérez-de-Luque, A., González-Verdejo, C. I., Lozano, M. D., Dita, M. A., Cubero, J. I., González-Melendi, P., Risueño, M. C., and Rubiales, D. 2006. Protein cross-linking, peroxidase and $\beta$-1,3-endoglucanase involved in resistance of pea against Orobanche crenata. J. Exp. Bot. 57:14611469.

25. Pérez-de-Luque, A., Jorrín, J., Cubero, J. I., and Rubiales, D. 2005. Resistance and avoidance against Orobanche crenata in pea (Pisum spp.) operate at different developmental stages of the parasite. Weed Res. 45:379-387.

26. Pérez-de-Luque, A., Lozano, M. D., Cubero, J. I., Gonzàlez-Melendi, P., Risueño, M. C., and Rubiales, D. 2006. Mucilage production during the incompatible interaction between Orobanche crenata and Vicia sativa. J. Exp. Bot. 57:931-942.

27. Pérez-de-Luque, A., Rubiales, D., Cubero, J. I., Press, M. C., Scholes, J., Yoneyama, K., Takeuchi, Y., Plakhine, D., and Joel, D. M. 2005. Interaction between Orobanche crenata and its host legumes: unsuccessful haustorial penetration and necrosis of the developing parasite. Ann. Bot. 95:935-942.

28. Rubiales, D. 2003. Parasitic plants, wild relatives and the nature of resistance. New Phytol. 160:459-461.

29. Rubiales, D., Alcántara, C., Joel, D. M., Pérez-de-Luque, A., and Sillero, J. C. 2003. Characterization of the resistance to Orobanche crenata in chickpea. Weed Sci. 51:702-707.

30. Rubiales, D., Pérez-de-Luque, A., Cubero, J. I., and Sillero, J. C. 2003. Crenate broomrape (Orobanche crenata) infection in field pea cultivars. 
Crop Prot. 22:865-872.

31. Rubiales, D., Pérez-de-Luque, A., Sillero, J. C., Román, B., Kharrat, M., Khalil, S., Joel, D. M., and Riches, C. 2006. Screening techniques and sources of resistance against parasitic weeds in grain legumes. Euphytica 147:187-199.

32. Rubiales, D., Verkleij, J., Vurro, M., Murdoch, A. J., and Joel, D. M. 2009. Parasitic plant management is sustainable agriculture. Weed Res. 49(Suppl. 1):1-5.

33. Serghini, K., Pérez de Luque, A., Castejón-Muñoz, M., García-Torres, L., and Jorrín, J. V. 2001. Sunflower (Helianthus annuus L.) response to broomrape (Orobanche cernua Loefl.) parasitism: induced synthesis and excretion of 7-hydroxylated simple coumarins. J. Exp. Bot. 52:22272234.

34. Sillero, J. C., Cubero, J. I., Fernández-Aparicio, M., and Rubiales, D. 2005. Search for resistance to crenate broomrape (Orobanche crenata) in Lathyrus. Lathyrus Lathyrism Newsl. 4:224-227.

35. Whitney, P. J., and Carsten, C. 1981. Chemotropic response of broomrape radicles to host root exudates. Ann. Bot. 48:919-921.

36. Yakota, T., Sakai, H., Okuno, K., Yoneyama, K., and Takeuchi, Y. 1998. Alectrol and orobanchol, germination stimulants for Orobanche minor, from its host red clover. Phytochemistry 49:1967-1973.

37. Yoder, I. J., and Scholes, D. J. 2010. Host plant resistance to parasitic weeds; Recent progress and bottlenecks. Curr. Opin. Plant Biol. 13:478484.

38. Yoneyama, K., Awad, A. A., Xie, X., Yoneyama, K., and Takeuchi, Y. 2010. Plant Cell Physiol. 51:1095-1103.

39. Yoneyama, K., Takeuchi, Y., and Yokota, T. 2001. Production of clover broomrape seed germination stimulants by red clover root requires nitrate but is inhibited by phosphate and ammonium. Physiol. Plant. 112:25-30.

40. Yoneyama, K., Xie, X., Yoneyama, K., and Takeuchi, Y. 2009. Strigolactones: structures and biological activities. Pest Manage. Sci. 65:467-470.

41. Yoneyama, K., Yoneyama, K., Takeuchi, Y., and Sekimoto, H. 2007. Phosphorus deficiency in red clover promotes exudation of orobanchol, the signal for mycorrhizal symbionts and germination stimulant for root parasites. Planta 225:1031-1038.

42. Zaitoun, F. M. F., Al-Menoufi, A. O., and Weber, C. H. 1991. Mechanisms of tolerance and susceptibility of three Vicia faba varieties to the infection with Orobanche crenata. Pages 195-207 in: Proc 5th Int. Symp. Parasitic Weeds. J. Ransom, L. J. Musselman, A. D. Worsham, and C. Parker, eds. CIMMYT, Nairobi, Kenya.

43. Zehhar, N., Labrousse, P., Arnaud, C. A., Boulet, C., Bouya, D., and Fer, A. 2003. Study of resistance to Orobanche ramosa in host (oilseed rape and carrot) and non-host (maize) plants. Eur. J. Plant Pathol. 109:75-82. 